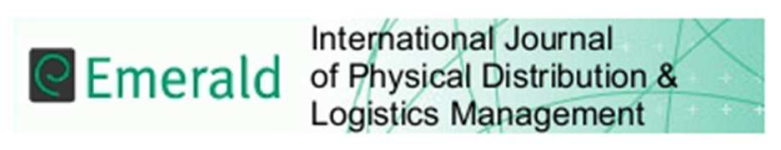

\title{
Supply Chain Finance: a literature review
}

\begin{tabular}{|r|l|}
\hline Journal: & International Journal of Physical Distribution \& Logistics Management \\
\hline Manuscript ID & IJPDLM-08-2014-0173.R4 \\
\hline Manuscript Type: & Research Paper \\
\hline Keywords: & $\begin{array}{l}\text { supply chain finance, supply chain management, literature review, supply } \\
\text { chain collaboration }\end{array}$ \\
\hline \multicolumn{2}{|l}{} \\
\hline
\end{tabular}




\title{
Supply Chain Finance: a literature review
}

\author{
Abstract \\ Purpose The purpose of this paper is twofold: to classify the research to-date on \\ Supply Chain Finance (SCF) according to the main themes and methods, and to \\ propose directions for future research. \\ Design/methodology/approach The review is based on 119 papers mainly \\ published from 2000 to 2014 in international peer-reviewed journals and in the \\ proceedings of international conferences. \\ Findings The articles that provide a definition of SCF reflect two major \\ perspectives: the 'finance oriented' perspective - focused on short-term solutions \\ provided by financial institutions, addressing accounts payable and receivable - \\ and the 'supply chain oriented' perspective - which might not involve a financial \\ institution, and is focused on working capital optimisation in terms of accounts \\ payable, receivable, inventories, and sometimes even on fixed asset financing. \\ Research limitations/implications While efforts were made to be all-inclusive, \\ significant research efforts may have been inadvertently omitted. However, the \\ authors believe that this review is an accurate representation of the body of \\ research on SCF published during the specified timeframe, and feel that \\ confidence may be placed on the resulting assessments. \\ Originality/value The paper presents a comprehensive summary of previous \\ research on this topic and identifies the most important issues that need to be \\ addressed in future research. On the basis of the identified gaps in the literature, \\ four key issues have been highlighted which should be addressed in future \\ research.
}

Keywords: supply chain management, supply chain finance, supply chain collaboration; literature review

Paper type: literature review

\section{Introduction}

The recent economic downturn caused a considerable reduction in the granting of new loans, with a significant increase in the cost of corporate borrowing (Ivashina and Scharfstein, 2010). Moreover, the collapse of the asset and mortgage-backed markets dried up liquidity from industries (Cornett et al., 2011). In these difficult times, firms (especially the most vulnerable ones) tried to extend trade credit from suppliers in order 
to supplement other forms of financing, while organisations less affected by this credit crunch took the role of liquidity providers, accepting an increase in payment terms (Coulibaly et al., 2013; Garcia-Appendini and Montoriol-Garriga, 2013). These effects contributed considerably to the need for solutions and programs that optimise working capital. Among these, one of the most important approaches is Supply Chain Finance (SCF) (Polak et al., 2012). SCF aims to optimise financial flows at an interorganisational level (Hofmann, 2005) through solutions implemented by financial institutions (Camerinelli, 2009) or technology providers (Lamoureux and Evans, 2011). The ultimate objective is to align financial flows with product and information flows within the supply chain, improving cash flow management from a supply chain perspective (Wuttke et al., 2013b). The benefits of the SCF approach rely on cooperation among players within the supply chain, which typically results in lower debt costs, new opportunities for obtaining loans (especially for 'weak' supply chain players), or reduced working capital within the supply chain. Moreover, the SCF approach often improves trust, commitment, and profitability throughout the chain (Randall and Farris II, 2009).

The level of interest in the topic of SCF among practitioners has increased significantly. An example that illustrates this is the 'Supply Chain Finance scheme' developed by the UK government [i]. This scheme is an agreement between the UK government and 37 of the biggest companies in the UK. The companies agree to notify a financial institution when an invoice is approved for payment; the bank is then able to offer a 100 per cent immediate advance to the supplier at a lower interest rate, knowing that the invoice will ultimately be paid by the large company.

Along with the expansion of the SCF market, interest in SCF is also growing among academics. The number of scientific articles focusing on SCF has increased in the last 
decade, giving the concept a more defined identity and leading to the development of a more precise framework to describe the SCF solutions landscape. However, contrasting definitions, which address the topic from different perspectives, have been found in the literature. More specifically, the literature review highlights the existence of the finance oriented and the supply chain oriented perspectives (cf. section 3). The former is focused on financial aspects and considers the SCF approach as a set of financial solutions, very often provided by financial institutions (Camerinelli, 2009). The latter emphasises the role of collaboration amongst supply chain members, with a particular focus on inventory optimisation. This perspective extends the boundaries of SCF beyond simply financial solutions, taking into consideration inventories, supply chain processes, and even collaborative solutions for fixed asset financing, such as pay-onproduction schemes (Pfohl and Gomm, 2009). The differences between the two perspectives result in conflicting frameworks and definitions, and consequently it is still very difficult to derive a clear picture of SCF from the existing literature. As a matter of fact, a general framework describing the SCF concept and SCF solutions, in which the two main perspectives (finance oriented and supply chain oriented) are both considered, is still lacking. The authors believe that the integration of these two existing perspectives is critical if the benefits of the SCF approach are to be more fully realised. This article aims to provide a systematic review of the recent literature and to identify areas for future research. The paper is organised as follows: the second section describes the methodology used to carry out this literature review; the third section presents and discusses the main findings; the fourth section highlights the gaps and suggests potential directions for future research in this field; and the final section presents the conclusions that have been drawn. 


\section{Methodology}

\section{Scope of the analysis}

This review examines articles dealing with the general concept of SCF and/or specific SCF solutions (e.g. factoring, reverse factoring, supplier finance, VMI - VendorManaged Inventory), mainly published between 2000 and 2014. As a matter of fact, although some specific solutions were addressed long before 2000, the rise of the SCF concept can reliably be said to have started at the beginning of the $21^{\text {st }}$ century (Hofmann, 2005; Pfohl and Gomm, 2009). Together with the aforementioned solutions, the trade credit literature was also reviewed, considering the same time frame. This literature could not be neglected in the present review, because it is recognised that trade credit partially overlaps with the concept of SCF (Klapper and Randall, 2011). Contributions focused on trade credit are plentiful within this time frame (Chang et al., 2008; Seifert et al., 2013; Soni et al., 2010). Specifically, they can be divided into seven groups: monetary policy implications, credit risk models, trade credit motives, order quantity decisions, factoring economics, credit term decisions, and settlement period decisions (Seifert et al., 2013). The first two groups in the list are unrelated to the matter at hand, and were therefore excluded from this review. The other categories might include contributions with clear links to the concept of SCF (e.g. Klapper et al., 2011; Klapper and Randall, 2011), and, therefore, were included in this review. It should be noted that several articles that address the topic of 'Financial supply chain management' have also been included in this review, based on the fact that, at least in these particular contributions, the distinction between SCF and Financial supply chain management seems to be negligible. Specifically, contributions dealing with the integration of physical and information flows with financial flows (Wuttke et al., 
2013b) were included, whereas articles which address the topic solely from the point of view of automating the trade process were excluded.

\section{Selection process}

The selection process can be divided into two macro-steps. In the first step, the search was conducted using library databases (e.g. Science Direct, Scopus, Web of Knowledge) and multiple keywords and strings (e.g. 'supply chain finance', 'supply chain financing', 'financial supply chain', 'financial value chain', 'working capital optimisation' 'working capital management' 'VMI', 'supply chain AND factoring', 'reverse factoring'), which were sought in both the abstract and in the main body of the paper. By using this method, all of the major logistics and supply chain management journals and the top finance and management journals were examined (e.g. International Journal of Physical Distribution and Logistics Management, Supply Chain Management: an international Journal, Journal of Business and Finance, Journal of Finance, Management Science, International Journal of Production Economics, Journal of Business Logistics, Journal of Supply Chain Management, Journal of Operations Management). In addition to international journals, the search included the proceedings of leading international conferences as well as published books. Articles that mentioned the SCF topic only in the introductory remarks or as a collateral research theme were discarded (e.g. articles focusing on e-invoicing, which only mention SCF, were considered to be out of scope).

Papers were read carefully and thoroughly. In the end, 106 papers published from 2000 to 2014 were selected for in-depth examination.

In the second step, coherently with Cooper (2009), the entire body of work referenced in the initial sample of 106 papers was gathered and examined, in order to identify relevant papers that: (i) eluded the keyword search carried out in step one, or (ii) were 
published prior to the time limit set (i.e. 2000). This step led to the identification of a total of 2016 articles, most of which could immediately be discarded based solely on the title (i.e. methodological, contextual, or other articles clearly unrelated to the topic at hand) or because they were already included in the initial sample of 106 articles. The result was a sample of 226 articles. From these, 50 additional contributions were discarded because they were found to be non-scientific articles (e.g. reports, white papers), leaving 176 articles to be reviewed. In order to select which articles deserved an in-depth analysis, two criteria were used: (i) papers published in a top journal (i.e. the top finance, logistics or supply chain management journals based on the SCImago Journal Ranking index), or (ii) if not published in a top journal (as defined above), papers that were cited in at least 4 of the original sample of 106 articles. The first criterion produced 20 articles, while the second produced 18. Each of these articles was then carefully examined to determine whether it should be included. Ultimately, 9 articles from the first group and 4 from the second were added to the review, bringing the total number of articles to 119.

Summarizing, 119 papers were selected. Among these, 5 were published before 2000, while the others were published in the 2000-2014 timeframe; 102 were published in journals, and 16 in international conference proceedings, while the remainder are books, book chapters and working papers. In general, the papers found on this topic were published in journals of logistics and supply chain management (22), business and management (14), economics (14), finance and treasury (11), production management (11), operations research (10), and engineering and technologies (7).

\section{Review method}

A number of methods used in previous reviews were examined (Meixell and Norbis, 2008; Natarajarathinam et al., 2009; Perego et al., 2011). For the purposes of our 
review, and consistently with Perego et al. (2011), the articles were classified using a two-pronged approach. The papers were classified on the basis of the research method(s) adopted and were also examined on the basis of their contents. The general Supply Chain Finance literature (not related to specific solutions) was analysed first in order to identify the main topics currently being studied and relevant SCF solutions to be included in the review. Then, articles related to those solutions were examined. All of the papers were grouped according to three main themes:

(1) concept and definitions of SCF;

(2) expected benefits;

(3) SCF initiatives in place.

The articles were summarised using the established review criteria in order to facilitate the identification of patterns that describe research themes as well as revealing possible gaps. Coherently with Carter and Easton (2011) and Jarvis et al. (2003), data coding was conducted by the corresponding author and by one of the other authors, based on the coding scheme depicted in Table 1. An initial measure of reliability, based on the proportion of total pairwise agreements between the coders, was (overall) over 80 percent, suggesting a very high level of reliability and thus replicability of the data coding (Carter and Easton, 2011). Disagreements between coders were examined, and the other authors were involved as needed, until consensus was reached (Jarvis et al., 2003; Pilbeam et al., 2012).

$====$ Please insert table 1 here $===$

Table 1: Categories used to extract and analyse the data

\section{Supply Chain Finance: findings from the literature}

This section is organised as follows: following a brief introduction, the articles are discussed from the point of view of the research method in the first subsection, while 
the subsequent subsections address the key topics listed in the previous section. A table summarising the content and features of each of the 119 papers analysed is available upon request.

\section{Research method}

The analysis presented in this paper replicates the categorisation proposed by Meixell and Norbis (2008), in which the papers were classified according to seven research methods, i.e. analytical models, conceptual models or frameworks, case studies, interviews, surveys, simulation and others. Please note that the total number of papers listed in Table 2 does not add up to 119 as multiple methodologies were used in some papers. Overall, about half of the articles reviewed are based on analytical models or simulations, while the other half are almost equally split between conceptual and empirical studies (e.g. case study, surveys).

$====$ Please insert table 2 here $====$

Table 2: Research method summary

Analytical modelling has been used with a general scope by some authors, such as Pfohl and Gomm (2009), who modelled a generic SCF solution in order to identify the variables driving the benefits. Similarly, Srinivasa Raghavan and Mishra, (2011), developed an analytical model to demonstrate that, under the right hypotheses, the joint financing of a buyer-supplier dyad is more profitable than two separate financing operations for both of the two organisations and for the lender. The analytical approach has, of course, also been used extensively to model specific SCF solutions. In this respect, the solution most commonly addressed is Vendor-Managed Inventory. Dong and $\mathrm{Xu}$ (2002), approached the solution from the supply chain perspective, and compared the benefits of the VMI solution to those that can be achieved through so- 
called full channel coordination (i.e. an ideal state in which the supply chain players concur to maximise the profit of the entire supply chain). Yao (2008), on the other hand, compared the benefit of Information Sharing, Continuous Replenishment, and VMI in terms of stock reduction with respect to a more traditional stock management policy. With regard to other solutions, Palia and Sopranzetti (2004) proposed a model to assess the benefits of a solution for the securitisation of accounts receivable (such as the factoring option), while Lee and Rhee (2011) demonstrated how trade credit, used according to a supply chain perspective, could be a valuable supply chain coordination tool.

The conceptual articles reviewed usually present general frameworks or concepts regarding $\mathrm{SCF}$, focused on defining the scope of application, the objectives, the actors involved, or the levers that can be exploited (Camerinelli, 2009; Gomm, 2010; Hofmann, 2005; Hofmann and Belin, 2011; Pfohl and Gomm, 2009). Hofmann (2005) provided an analysis of the players involved in the SCF process as well as some insights about how SCF solutions affect the way financial and supply chain processes are managed. Although conceptual papers dealing with the SCF concept are much more prevalent than those involving specific SCF solutions, some valuable examples of the latter were found, e.g. Soufani (2001) addressed the role of factoring for SMEs in the UK.

With regard to empirical research methodologies, the literature reviewed highlights the use of surveys (Borade and Bansod, 2010; Dong et al., 2007; Klapper, 2006; Soufani, 2002), as well as statistical analyses of empirical data from previous datasets (Atanasova, 2012; Fisman and Love, 2003; Klapper, 2006). As an example, More and Basu (2013) conducted a survey of Indian firms, whose purpose was to identify the most important challenges in the implementation of SCF solutions. In addition, the case 
study methodology has recently been used in several articles, in a descriptive (Blackman et al., 2013; Randall and Farris II, 2009) or in an exploratory manner (Wuttke et al., 2013a, 2013b). These articles usually examine the resulting benefits and, in some cases, present interpretative SCF frameworks. Notably, (Wuttke et al., 2013a), used case studies to develop a six-proposition framework linking the contextual variables and the internal supply chain characteristics that most affect the application of SCF solutions.

\section{Concept and definitions}

This section discusses the definitions of SCF presented in the papers analysed, which are summarised in Table 3. These definitions help clarify the current state of the art in SCF and the main perspctives from which different authors have approached this topic.

$====$ Please insert Table 3 here $===$

Table 3: Supply Chain Finance definitions

In order to classify the definitions of SCF, two main factors were considered:

(a) The role of financial institutions

(b) The scope of SCF

(i) Only (an evolved form of) Reverse Factoring

(ii) Inclusive of inventory optimisation and/or inventory shifting

(iii) Inclusive of fixed asset financing

Variable (a) deals with the role of financial institutions within the SCF framework. Some articles suggest that SCF can be considered as a set of short-term solutions provided by financial institutions, focused on accounts payable and/or receivable. In 
these articles, the direct involvement of a lender, who becomes the solution provider, is an essential component of the SCF scheme.

Variable (b) reflects the scope of SCF covered in the selected articles. Some of these papers not only consider SCF as a set of short-term financial solutions, but also limit the possible financial solutions to Reverse Factoring only, assuming a specific buyer-driven orientation (typical of Reverse Factoring).

Other papers include collaborative inventory management or inventory shifting among supply chain players within SCF. The inclusion of inventories as well as payables and receivables broadens the scope of SCF to include working capital in its entirety.

Finally, some articles further expand the scope of SCF. These, in fact, not only consider all of the working capital components as the main target of SCF practices, but expand the scope to include the financing of fixed assets among supply chain players (Gomm, 2010; Hofmann, 2005; Pfohl and Gomm, 2009).

Two major perspectives emerge from the analysis of the articles that provide definitions of SCF: the 'finance oriented' (from which it is possible to identify a further 'buyerdriven' perspective) and the 'supply chain oriented' perspective (cf. Table 4).

\footnotetext{
$===$ Please insert table 4 here $===$

Table 4: The SCF perspectives identified.
}

The 'finance oriented' perspective interprets SCF as a set of (innovative) short-term financial solutions, as shown by Camerinelli (2009) and Chen and $\mathrm{Hu}$ (2011), who explicitly mentioned this point in their definitions. Therefore, financial institutions (or, more generally, lenders) are essential components in the SCF scheme. A second important characteristic of the 'finance oriented' perspective is the focus on payables and receivables (but not on inventories). Lamoureux and Evans (2011) opine that the 
events that trigger SCF solutions are the most important events in the trade process (e.g. order acceptance, shipment, payable due date). This view is also held by More and Basu (2013), for whom SCF is conceptually divided into three categories: pre-shipment, intransit, and post-shipment financing solutions. It is worth noting that, within the 'finance oriented' perspective, there is also a subset of articles that address SCF from an even stricter perspective, which could be called the 'buyer-driven' perspective. In these articles, SCF is viewed as a set of buyer-driven financial solutions, often modelled as an evolved form of Reverse Factoring (Seifert, 2010; Wuttke et al., 2013b). The evolution, with respect to traditional Reverse Factoring, lies mainly in the technological improvement of the solution that makes it possible to: (i) provide capital to a higher number of suppliers at a lower rate, (ii) increase transparency and flexibility, and (iii) involve new players - such as logistics service providers (Chen and $\mathrm{Hu}, 2011$; Wuttke et al., 2013b). Although this perspective is taken into account in only a limited number of articles, it is quite well-established among practitioners (PWC, 2009).

On the other hand, the 'supply chain oriented' perspective extends the framework of working capital optimisation to include inventories. For example, Pfohl and Gomm (2009) tested their conceptual model in a VMI scenario, while Randall and Farris II (2009) analysed the benefits achieved through a generic shifting of inventory between two supply chain players. In the latter case, a descriptive case study highlights how all of the different components of the cash-to-cash (C2c) cycle can be managed in a collaborative way by the supply chain players involved (e.g.: shifting inventories from a supplier to a customer). Notably, the described benefits might be achieved in the absence of a specific financial solution provided by a lender, which, in fact, is often ancillary. As a general trend, the articles that take this perspective tend to provide holistic analyses of the SCF approach, without describing any specific solutions or 
practices. A second characteristic of some of the papers that assume the 'supply chain oriented' perspective regards the object of the financing. Pfhol and Gomm (2009), and Gomm (2010), specifically state that SCF also applies to fixed asset financing (e.g.: through a pay per production solution). This is also confirmed by Hofmann (2005), who illustrates, as an example of an SCF operation, a joint investment in a fixed asset by two organisations that are part of the same supply chain.

\section{Expected benefits}

From a strictly financial point of view, the benefits of SCF solutions derive mostly from the exploitation of differences in the cost of capital between different players in the supply chain (Lamoureux and Evans, 2011). This is a well-known fact, which was identified even in early contributions on specific SCF models (such as Reverse Factoring), published well before the 2000s, already underline it (Brennan et al., 1988). Player ' $\mathrm{A}$ ', whose cost of capital is $k_{A}$, might exploit the cost of capital $k_{B}\left(k_{B}<k_{A}\right)$ of player ' $\mathrm{B}$ ' in order to lower its capital rate (Pfohl and Gomm, 2009; Randall and Farris II, 2009). However, this is not the only source of benefit and, in order to better conceptualise the value derived from a SCF program, two additional factors should be taken into account: the duration and volume of the financing required. This threedimensional framework is known as the 'Supply Chain Finance cube', and was proposed by Pfohl and Gomm (2009) and Gomm (2010). The different SCF solutions affect one or more of the three axes that define the cube. For example, a VendorManaged Inventory program directly affects the volume of capital needed, decreasing inventories through improved accuracy (Dong et al., 2007; Sari, 2007); an invoice discounting solution directly affects the duration of the financing, decreasing the cashto-cash cycle for the supplier and/or the buyer involved in the transaction (Farris II and Hutchison, 2002; Grosse-Ruyken et al., 2011); a Reverse Factoring solution, or in 
general a program that combines the shortening of the cash-to-cash cycle with the exploitation of the leading player's risk rating, affects both the duration and the rate axes (Wuttke et al., 2013a).

The benefits of SCF solutions, however, are not limited to financial performance. Supply chain visibility is of paramount importance as well (Caridi et al., 2010). Large companies (such as player ' $\mathrm{B}$ ' in the previous example) might be interested in promoting SCF solutions in order to lower the cost of gathering certain information (e.g. customer demand), which is too costly or even impossible to gather otherwise (Pfohl and Gomm, 2009), thus increasing its total sales or reducing its costs.

Another very important source of benefit for large supply chain players is the reduced risk of bankruptcy throughout the supply chain. This kind of benefit is typical of factoring and Reverse Factoring solutions. Specifically, Klapper (2006) points out that factoring (and, moreover, Reverse Factoring) may allow high-risk suppliers to mitigate their credit risk level with that of their high-quality buyers, thus reducing their cost of debt and increasing their level of access to liquidity. The Reverse Factoring solution could provide additional benefits related to the reduced need for information: collecting credit information for selected high-quality buyers is - generally speaking - easier and reduces the risk of the financial operation, with a further decrease in cost of debt and access to liquidity for high-risk suppliers (Berger and Udell, 2006; Klapper, 2006; Tanrisever et al., 2012).

Several papers approach the analysis of SCF benefits from the point of view of the cashto-cash cycle, which is also typically a key performance indicator for the management of the entire supply chain (Farris II and Hutchison, 2002). The cash-to-cash cycle can be defined as 'the average days required to turn a dollar invested in raw materials into 
a dollar collected from a customer' (Stewart, 1995) and it consists of three components: days of sales outstanding (accounts receivable collection period) plus days of inventory held (considering both work-in-progress and finished products) minus days of payable outstanding (accounts payable settlement period). As an example, Luo and Zhang (2012) studied the benefits of coordinating the supply chain through trade credit (i.e. operating on the accounts receivable collection period). Their results show that managing trade credit periods might be a source of substantial benefits for the supply chain. For example, a low-risk buyer can use trade credit to financially sustain a start-up supplier, to mutual benefit. However, the authors also demonstrated that such benefits depend on the information available throughout the chain: asymmetric information among the parties involved may lead to suboptimal solutions. Along the same line of reasoning, Hofmann and Kotzab (2010) showed how a collaborative approach (or, as it is called, a supply chain-oriented approach) to cash-to-cash management leads to optimal solutions, whereas aggressive behaviour (i.e. pressure to shorten receivable collection and extend payable settlement times through the supply chain) might negatively affect the value of the organisations involved. Such conceptual insights also find support among practitioners, as some organisations have adopted the role of liquidity providers, accepting an increase in their cash-to-cash cycle, providing an alternative means of financing to supply chain partners in distress. The positive effects of an SCF approach to cash-to-cash cycle management are also confirmed by Lamoureux and Evans (2011), and by Randall and Farris II (2009).

Other articles highlight the benefits associated with the involvement of financial institutions in SCF programs. In some solutions, such as factoring or those focused on securitising assets receivable, financial institutions usually carry the burden of collecting payments, in exchange for an increase in revenues (Palia and Sopranzetti, 
2004; Tanrisever et al., 2012). Moreover, financial institutions can improve their riskassessment process, especially regarding SMEs. This assessment is often characterised by high levels of uncertainty due to asymmetric information, and constitutes a source of major concern for financial institutions (Deakins and Hussain, 1994). The SCF approach might increase the availability and accuracy of information, thus supporting financial institutions in estimating a default probability tailored to the specific SMEs (Hofmann, 2005).

Finally, some articles state that supply chain links are strengthened through enhanced collaboration, visibility or automation that a SCF solution might entail (Hofmann and Belin, 2011; Lamoureux and Evans, 2011).

\section{Supply Chain Finance projects}

Several papers describe existing SCF initiatives (Blackman et al., 2013; More and Basu, 2013; Templar et al., 2012; Wuttke et al., 2013a, 2013b). Overall, these articles can be categorised into two classes, based on their purpose. Some of them are descriptive in nature, and present one or more cases of interest, highlighting significant aspects; others are exploratory and present a set of propositions related to SCF about the adoption process, the outcome of the SCF program or the role of inter- or intra-company collaboration.

(i) Descriptive: the purpose of these articles is usually to highlight successful examples of SCF programs or practices. The paper can have a single- or multi-case focus. The papers analysed present the descriptive case studies either as the main contribution to the paper, or to support insights gathered conceptually. An example of the first type, with a single-case focus, is the analysis of the Motorola financial supply chain management strategy, described by (Blackman et al., 2013). The 
authors highlight how the introduction of a collaborative approach to managing the financial flows within the supply chain generates cost savings for all of the companies involved.

An example of the multi-case type is presented by (John Mathis and Cavinato, 2010), in which the Zara and Toyota financial supply chain strategies are described in order to demonstrate that collaboration between the finance and supply chain functions is paramount for an effective financial supply chain management strategy. A second example is represented by (Nienhuis et al., 2013), who analysed the opportunities presented by SCF in terms of real-time financing of SMEs. They discussed two descriptive case studies focused on innovative SCF services, which support the conclusion that e-invoicing service providers and financial institutions are moving towards real-time financing. A further example is represented by (Silvestro and Lustrato, 2014), who analysed the role of banks in the integration of financial and physical flows, and supported their conceptual conclusions with two in-depth case studies.

(ii) Exploratory: the purpose of these articles is to develop, from multiple SCF initiatives, a series of propositions regarding contextual and/or internal variables that might affect the adoption process and/or the benefits of different SCF solutions. As an example, Wuttke et al. (2013b), who adopted a multi-case methodology, identified patterns related to contextual and internal variables affecting the adoption process and the outcomes of the different SCF solutions. They developed a five-proposition framework with the objective of supporting managerial decisions related to the implementation of SCF programs. Similarly, Wuttke et al. (2013a) used a number of case studies to develop four propositions involving the adoption process. Specifically, the authors addressed why companies take different approaches to SCF, and the role of 
suppliers in the adoption of SCF solutions.

Another analysis that is based on exploratory case studies is provided by Templar et al. (2012). The authors collected empirical evidence from different industries for the purpose of analysing motivations, strategies, enablers and inhibitors of different SCF applications. The paper provides a twofold contribution: the authors highlight how SCF impacts on both the supply chain and the financial performance of the companies involved, and they also point out the current level of immaturity of SCF practices in business, and the existing gap between SCF theory and practice which does, however, seem to be decreasing.

\section{Gaps and directions for future research}

Four main gaps have been identified in the literature reviewed. Consequently, recommendations for future research have been provided to fill in these gaps.

\section{(i) No general theory of SCF}

The most important gap in the current SCF literature is the lack of a general 'theory of $S C F$ '. This seems to be the cause of the disparity between SCF theory and practice, which has previously been noted by Templar et al. (2012). This is hardly surprising. On the one hand, SCF is a complex and relatively new concept, but on the other hand, the division of this topic into two different persectives has led to the publication of diconnected ideas, which has had a negative impact on the usefulness of the results. The research on this topic should therefore move from a conceptual determination of the validity and importance of SCF (which has been achieved) on to addressing and generalising the building blocks of this approach (e.g. schemes and solutions, issues, enablers), starting with a comprehensive definition of those practical instruments or solutions that make up the SCF landscape. A better general theory of SCF can be 
developed if it is based on a solid foundation of broadly applicable SCF building blocks. The reviewed literature is not devoid of attempts to develop generalised visions of SCF that have been found among both the 'finance oriented' perspective (More and Basu, 2013) and the 'supply chain oriented' perspective papers (Wuttke et al., 2013a, 2013a). However, they are relatively scarce and the ideas presented have not been fully developed, since they usually address just a few practices without providing a holistic framework. Moreover, they still fail to bridge the two main perspectives, producing efforts and publications that are not fully coherent among each other.

Further research works should focus on providing a comprehensive classification of SCF solutions that takes into consideration the key features of SCF practices and takes a more practical view of the SCF concept. These definitions will be the building blocks for the creation of a general SCF theory following a theory generation process similar to the one observed within the field of supply chain management (Carter et al., 2015; Cooper et al., 1997; Croxton et al., 2001).

(ii) Weak empirical-based holistic analyses on the application of SCF

Although analyses of specific SCF solutions (e.g. factoring, trade credit and VMI, Claassen et al., 2008; Klapper and Randall, 2011; Klapper, 2006) based on empirical data have been found in the literature, there is a lack of empirical analyses addressing SCF from a more holistic point of view (e.g. state of the art/adoption level of the different SCF solutions). Empirical analyses might prove useful for testing existing models and hypotheses, as highlighted by Pfohl and Gomm (2009), as well as providing data for an assessment of the diffusion of the SCF approach and of its different applications, which is still unclear. The existing empirical studies do not fully satisfy this need. Among the most significant empirical studies, More and Basu (2013) based their work on a survey, which was limited to financial solutions - a limitation shared 
also by Wuttke et al., 2013a - and, geographically, to Indian firms only. Wuttke et al. (2013b), considered a more comprehensive set of practices (such as evolved forms of Reverse Factoring, inventory financing, and financing based on letters of credit), but limited the study to the application of SCF solutions focused on the upstream side of the supply chain.

Further research should address more innovative schemes and solutions (such as Dynamic Discounting, or evolved forms of Reverse Factoring) and also tackle the application of SCF solutions that focus on the downstream side of the supply chain, as these have received less attention, especially from the empirical point of view. Future research should also focus on analysing the adoption level and the state of the art of the different solutions. Finally, empirical studies should be employed to test hypotheses and the models developed.

(iii)Few assessment models consider the impact of SCF programs on Supply Chain financial performance

Although the link between the SCF concept and a financially sustainable supply chain has already been addressed (Templar et al., 2012), there is a general lack of research on the effects of SCF solutions on the financial performance of the entire supply chain (i.e. with supply chain set-ups that are more complex than the single buyer-supplier dyad). The literature on the 'finance oriented' perspective includes a series of SCF solutions that have been recognised to have a positive effect on the financial performance of the supply chain players, although further research is still needed to better assess some of the more innovative solutions (e.g. Dynamic Discounting and evolved form of Reverse Factoring). One example is the Reverse Factoring solution, which positively influences the financial performance of the supply base involved (Klapper, 2006). However, quantitative assessments of the benefits achievable through Reverse Factoring solutions 
are still rare and are based on the single buyer-supplier set up (e.g. Tanrisever et al. 2012). A second example is the management of trade credit, which has been considered by a number of authors who focused on the impact on the financial variables - such as the cost of capital - of the supply chain players involved. Although the management of trade credit has been addressed for a range of scenarios, which generally involve typical supply chain or logistics decisions (e.g. joint inventory policies and trade credit decisions, trade credit for the supply chain coordination), non-dyadic supply chain setups have scarcely been addressed and have been identified as an area for future research (Seifert, 2010).

With regard to the SCF 'supply chain oriented' perspective, joint inventory management policies have been extensively analysed, even in complex networks, over a long period of time (Clark and Scarf, 1960). Specific 'supply chain oriented' SCF solutions (e.g. VMI) involving complex, non-dyadic supply chain set-ups have also been studied (Darwish and Odah, 2010; Mangiaracina et al., 2012). However, the impacts on the financial performance of the supply chain have rarely been addressed. A rare example is $\mathrm{Xu}$ et al. (2010), who analysed how VMI might reduce the probability of bankruptcy among supply chain players. The contributions that do consider financial performance are rudimentary and this topic could be further studied and developed in greater detail.

Future research should extend the focus of the assessment models either to include more complex supply chain set-ups (especially for solutions of a more financial nature), or to conduct a more comprehensive analysis of the impact on financial performance (especially with respect to solutions of a more supply chain management nature).

\section{(iv) Lack of tools for choosing SCF solutions for different Supply Chains and} objectives 
This review highlights a lack of practical guidance and tools to help managers identify the SCF solution that best suits their needs. This area has generally been neglected in the literature. Although some managerial implications have been identified, especially through empirically-based research such as that presented by Wuttke et al. (2013a, 2013b), no significant steps have been taken to develop such tools. These tools should be based upon an understanding of the benefits and drawbacks of the different SCF solutions, and at the same time upon the connection between the features of a supply chain and the different SCF solutions. As pointed out by Wuttke et al. (2013b), such variables (e.g. captivity, strategic importance, complexity of the market) have, in fact, an overriding effect on the effective application of different SCF solutions. As an example, a supply base consisting of SMEs responds in a different way to different SCF solutions than does a supply base made up of large companies, even if their financial performance is similar.

\section{Conclusions}

In this paper, 119 research contributions on the topic of Supply Chain Finance, mainly published between 2000 and 2014, were examined. The papers were analysed using a two-pronged approach - i.e. analysis of the research method(s) adopted and of the specific contents.

The contribution of this paper is twofold. First, it presents a structured review that provides a guide to both researchers and practitioners on the subject of SCF, highlighting the main perspectives that researchers have taken on this topic, the most important achievable benefits, and the methodologies used to conduct the studies. Second, it identifies some research issues for future investigation.

In general, the literature review has shown that the topic of SCF has been addressed from two main perspectives. The 'finance oriented' perspective is focused on short-term 
financial solutions, provided by financial institutions, which involve accounts payable and receivable. An even more restrictive perspective, the so-called buyer-driven perspective, focuses only on evolved forms of Reverse Factoring. The 'supply chain oriented' perspective, instead, is more broadly focused on working capital optimisation (in terms of accounts payable, receivable, and inventories) and potentially even on fixed asset financing. It may or may not include financial institutions, as it also comprises solutions that optimise working capital among the supply chain members. With regard to the benefits of SCF, the literature review has shown that tangible benefits can be found in the reduction of volume, rate, or duration of the financing, whereas intangible benefits can be achieved by exploiting the value of information and the strength of the supply chain links. In terms of methodology, the review shows that studies focusing on the general scope of SCF are mainly conceptual, whereas those focusing on specific solutions use analytical modelling and simulation.

The analysis revealed several gaps in the extant literature that indicate directions for future research in the area of SCF. First, it shows that there is a need for the development of a 'general theory of SCF'. Second, the empirical results on the application of many SCF solutions are weak. Third, there is lack of analysis focused on the link between SCF and supply chain financial performance. Finally, there are too few practical instruments available to support managerial decisions in the field.

This study has one potential limitation. While considerable effort was made to ensure that the review would be all-inclusive, it is possible that some relevant research studies may have inadvertently been omitted. However, the authors believe that this review is an accurate representation of the body of research on SCF published during the specific time frame. 


\section{References}

Atanasova, C. (2012), "How Do Firms Choose Between Intermediary and Supplier Finance?", Financial Management, Vol. 41 No. 1, pp. 207-228.

Berger, A. N., \& Udell, G. F. (2006), "A more complete conceptual framework for SME finance", Journal of Banking \& Finance, Vol. 30 No. 11, pp. 2945-2966.

Blackman, I. D., Holland, C. P., \& Westcott, T. (2013), "Motorola's global financial supply chain strategy", Supply Chain Management: An International Journal, Vol. 18 No. 2, pp. 132-147.

Borade, A. B., \& Bansod, S. V. (2010), "Study of vendor-managed inventory practices in Indian industries”, Journal of Manufacturing Technology Management, Vol. 21 No. 8, pp. 1013-1038.

Camerinelli, E. (2009), "Supply chain finance”, Journal of Payments Strategy \& Systems, Vol. 3 No. 2, pp. 114-128.

Caridi, M., Crippa, L., Perego, A., Sianesi, A., \& Tumino, A. (2010), "Measuring visibility to improve supply chain performance: a quantitative approach”, Benchmarking: An International Journal, Vol. 17 No. 4, pp. 593-615.

Carter, C. R., Rogers, D. S., \& Choi, T. Y. (2015), “Toward the Theory of the Supply Chain”, Journal of Supply Chain Management, Vol. 51 No. 2, pp. 89-97.

Chang, C.-T., Teng, J.-T., \& Goyal, S. K. (2008), "Inventory lot-size models under trade credits: A review", Asia-Pacific Journal of Operational Research, Vol. 25 No. 1, pp. 89-112.

Chen, X., \& Hu, C. (2011), "The Value of Supply Chain Finance”, In Habib, M. (Ed.), Supply Chain Management - Applications and Simulations, InTech, pp. 111-132.

Claassen, M. J., Van Weele, A. J., \& Van Raaij, E. M. (2008), "Performance outcomes and success factors of vendor managed inventory (VMI)", Supply Chain Management: An International Journal, Vol. 13 No. 6, pp. 406-414.

Clark, A. J., \& Scarf, H. (1960), “Optimal Policies for a Multi-Echelon Inventory Problem”, Management Science, Vol. 6 No. 4, pp. 475-490.

Cooper, H. M. (2009), Research Synthesis and Meta-Analysis: A Step-by-Step Approach, SAGE Publications, Inc., Los Angeles.

Cooper, M. C., Lambert, D. M., \& Pagh, J. D. (1997), "Supply chain management: more than a new name for logistics", International Journal of Logistics Management, The, Vol 8 No. 1, pp. 1-14. 
Cornett, M. M., McNutt, J. J., Strahan, P. E., \& Tehranian, H. (2011), "Liquidity risk management and credit supply in the financial crisis", Journal of Financial Economics, Vol. 101 No. 2, pp. 297312.

Coulibaly, B., Sapriza, H., \& Zlate, A. (2013), "Financial frictions, trade credit, and the 2008-09 global financial crisis", International Review of Economics \& Finance, Vol. 26, No. C, pp. 25-38.

Croxton, K. L., García-Dastugue, S. J., Lambert, D. M., \& Rogers, D. S. (2001), "The Supply Chain Management Processes", The International Journal of Logistics Management, Vol. 12, No. 2, pp. 13-36.

Darwish, M. A., \& Odah, O. M. (2010), "Vendor managed inventory model for single-vendor multiretailer supply chains”, European Journal of Operational Research, Vol. 204 No. 3, pp. 473484.

Deakins, D., \& Hussain, G. (1994), “Risk Assessment with Asymmetric Information”, International Journal of Bank Marketing, Vol. 12 No. 1, pp. 24-31.

Dong, Y., \& Xu, K. (2002), “A supply chain model of vendor managed inventory”, Transportation Research Part E: Logistics and Transportation Review, Vol. 38 No. 2, pp. 75-95.

Dong, Y., Xu, K., \& Dresner, M. (2007), "Environmental determinants of VMI adoption: an exploratory analysis", Transportation Research Part E: Logistics and Transportation Review, Vol. 43 No. 4, pp. $355-369$.

Farris II, M. T., \& Hutchison, P. D. (2002), "Cash-to-cash: the new supply chain management metric", International Journal of Physical Distribution \& Logistics Management, Vol. 32 No. 4, pp. 288298.

Fisman, R., \& Love, I. (2003), “Trade credit, financial intermediary development, and industry growth”, The Journal of Finance, Vol. 58 No. 1, pp. 353-374.

Garcia-Appendini, E., \& Montoriol-Garriga, J. (2013), "Firms as liquidity providers: Evidence from the 2007-2008 financial crisis”, Journal of Financial Economics, Vol. 109 No. 1, pp. 272-291.

Gomm, M. L. (2010), "Supply chain finance: applying finance theory to supply chain management to enhance finance in supply chains”, International Journal of Logistics Research and Applications, Vol. 13, No. 2, pp. 133-142. 
Grosse-Ruyken, P. T., Wagner, S. M., \& Jonke, R. (2011), "What is the right cash conversion cycle for your supply chain?”, International Journal of Services and Operations Management, Vol. 10 No. 1, pp. 13-29.

Hofmann, E. (2005), “Supply Chain Finance: some conceptual insights”, In Lasch, R. \& Janker, C. G. (Ed.), Logistik Management. Innovative Logistikkonzepte, German Universitätsverlag, Wiesbaden, pp. 203-214.

Hofmann, E., \& Belin, O. (2011), Supply Chain Finance Solutions, Springer-Verlag Berlin Heidelberg, Berlin.

Hofmann, E., \& Kotzab, H. (2010), “A Supply Chain-Oriented Approach of Working Capital Management”, Journal of Business Logistics, Vol. 31 No. 2, pp. 305-330.

Ivashina, V., \& Scharfstein, D. (2010), "Bank lending during the financial crisis of 2008", Journal of Financial Economics, Vol. 97 No. 3, pp. 319-338.

John Mathis, F., \& Cavinato, J. (2010), "Financing the global supply chain: Growing need for management action", Thunderbird International Business Review, Vol. 52 No. 6, pp. 467-474.

Klapper, L. F. (2006), "The role of factoring for financing small and medium enterprises", Journal of Banking \& Finance, Vol. 30 No. 11, pp. 3111-3130.

Klapper, L. F., Laeven, L., \& Rajan, R. (2011), “Trade credit contracts”, Review of Financial Studies, Vol. 25 No. 3, pp. 838-867.

Klapper, L. F., \& Randall, D. (2011), "Financial Crisis and Supply-Chain Financing”, in Chauffour J. \& Malouche M. Trade Finance during the Great Trade Collapse, The World Bank, Washington DC.

Lamoureux, J.-F., \& Evans, T. A. (2011), "Supply Chain Finance: A New Means to Support the Competitiveness and Resilience of Global Value Chains”, working paper 2179944, Social Science Research Network, Rochester, NY.

Luo, J., \& Zhang, Q. (2012), “Trade credit: A new mechanism to coordinate supply chain”, Operations Research Letters, Vol. 40 No. 5, pp. 378-384.

Mangiaracina, R., Melacini, M., \& Perego, A. (2012), “A critical analysis of vendor managed inventory in the grocery supply chain", International Journal of Integrated Supply Management, Vol. 7 No. 1-2, pp. $138-166$. 
Meixell, M. J., \& Norbis, M. (2008), “A review of the transportation mode choice and carrier selection literature", International Journal of Logistics Management, The, Vol. 19, No. 2, pp. 183-211.

More, D., \& Basu, P. (2013), “Challenges of supply chain finance: A detailed study and a hierarchical model based on the experiences of an Indian firm", Business Process Management Journal, Vol. 19, No. 4, pp. 624-647.

Natarajarathinam, M., Capar, I., \& Narayanan, A. (2009), "Managing supply chains in times of crisis: a review of literature and insights", International Journal of Physical Distribution \& Logistics Management, Vol. 39 No. 7, pp. 535-573.

Nienhuis, J. J., Cortet, M., \& Lycklama, D. (2013), "Real-time financing: Extending e-invoicing to realtime SME financing”, Journal of Payments Strategy \& Systems, Vol. 7 No. 3, pp. 232-245.

Palia, D., \& Sopranzetti, B. J. (2004), "Securitizing Accounts Receivable”, Review of Quantitative Finance and Accounting, Vol. 22 No. 1, pp. 29-38.

Perego, A., Perotti, S., \& Mangiaracina, R. (2011), "ICT for logistics and freight transportation: a literature review and research agenda", International Journal of Physical Distribution \& Logistics Management, Vol. 41 No. 5, pp. 457-483.

Pfohl, H. C., \& Gomm, M. (2009), "Supply chain finance: optimizing financial flows in supply chains", Logistics Research, Vol. 1 No. 3, pp. 149-161.

Polak, P., Sirpal, R., \& Hamdan, M. (2012), "Post-Crisis Emerging Role of the Treasurer”, European Journal of Scientific Research, Vol. 86 No. 3, pp. 319-339.

PWC (2009), "Demistify Supply Chain Finance - Insight into the what, why, how, where and who", available at: http://www.pwc.com/us/en/issues/surviving-the-financialdownturn/assets/supply_chain_finance.pdf (accessed 22 January 2016).

Raghavan, S. N. R., \& Mishra, V. K. (2011), "Short-term financing in a cash-constrained supply chain”, International Journal of Production Economics, Vol. 134 No. 2, pp. 407-412.

Randall, W., \& Farris II, T. (2009), "Supply chain financing: using cash-to-cash variables to strengthen the supply chain”, International Journal of Physical Distribution \& Logistics Management, Vol. 39 No. 8 , pp. 669-689.

Sari, K. (2007), "Exploring the benefits of vendor managed inventory", International Journal of Physical Distribution \& Logistics Management, Vol. 37 No. 7, pp. 529-545. 
Seifert, D. (2010), Collaborative Working Capital Management in Supply Networks, École Polytechnique Fédérale De Lausanne, Lausanne.

Seifert, D., Seifert, R. W., \& Protopappa-Sieke, M. (2013), “A review of trade credit literature: Opportunities for research in operations”, European Journal of Operational Research, Vol. 231 No. 2, pp. 245-256.

Silvestro, R., \& Lustrato, P. (2014), “Integrating financial and physical supply chains: the role of banks in enabling supply chain integration", International Journal of Operations \& Production Management, Vol. 34 No. 3, pp. 298-324.

Soni, H., Shah, N. H., \& Jaggi, C. K. (2010), "Inventory models and trade credit: a review", Control and Cybernetics, Vol. 39 No. 3, pp. 867-882.

Soufani, K. (2001), “The role of factoring in financing UK SMEs: a supply side analysis”, Journal of Small Business and Enterprise Development, Vol. 8 No. 1, pp. 37-46.

Soufani, K. (2002), "On the determinants of factoring as a financing choice: evidence from the UK", Journal of Economics and Business, Vol. 54 No. 2, pp. 239-252.

Stewart, G. (1995), "Supply chain performance benchmarking study reveals keys to supply chain excellence", Logistics Information Management, Vol. 8 No. 2, pp. 38-44.

Tanrisever, F., Cetinay, H., \& Reindorp, M., (2012), "Value of Reverse Factoring in Multi-stage Supply Chains”, paper presented at the 2011 MSOM Annual Conference, June 26-28, 2011, Ann Arbor, Michigan, available at: http://www.bus.umich.edu/Conferences/msom2011/GetFile.aspx?paper_ord=17475 (accessed 20 January, 2016).

Templar, S., Cosse, M., Camerinelli, E., \& Findlay, C. (2012), “An Investigation into Current Supply Chain Finance Practices in Business: a case study approach”, in Proceedings of the Logistics Research Network (LRN) Conference. Cranfield (UK).

Wuttke, D. A., Blome, C., Foerstl, K., \& Henke, M. (2013a), "Managing the Innovation Adoption of Supply Chain Finance-Empirical Evidence From Six European Case Studies”, Journal of Business Logistics, Vol. 34 No. 2, pp. 148-166.

Wuttke, D. A., Blome, C., \& Henke, M. (2013b), "Focusing the financial flow of supply chains: An empirical investigation of financial supply chain management”, International Journal of Production Economics, Vol. 145 No. 2, pp. 773-789. 
1

2

3

4

5

6

7

8

9

10

11

12

13

14

15

16

17

18

19

20

21

22

23

24

25

26

27

28

29

30

31

32

33

34

35

36

37

38

39

40

41

42

43

44

45

46

47

48

49

50

51

52

53

54

55

56

57

58

59

60

Xu, X., Sun, Y., \& Hua, Z. (2010), "Reducing the Probability of Bankruptcy Through Supply Chain Coordination", IEEE Transactions on Systems, Man, and Cybernetics, Part C: Applications and Reviews, Vol. 40 No. 2, pp. 201-215.

[i] Gov.uk. "Prime Minister announces Supply Chain Finance scheme - News stories GOV.UK." 2012. https://www.gov.uk/government/news/prime-minister-announcessupply-chain-finance-scheme (accessed 3 Feb 2014). 
Table 1. Categories used to extract and analyse the data

\begin{tabular}{|c|c|c|}
\hline Area & Category & Information \\
\hline \multirow[t]{3}{*}{ Descriptive } & Country & Country of corresponding author's affiliation \\
\hline & Source & $\begin{array}{l}\text { Journal, conference proceedings, or book title, in which } \\
\text { it was published }\end{array}$ \\
\hline & Title & Complete title of the paper \\
\hline \multirow[t]{2}{*}{ Methods } & Methodologies & $\begin{array}{l}\text { Primary methodology of the paper (cf. Table } 2 \text { for } \\
\text { admissible values); if a single primary methodology } \\
\text { cannot be identified, multiple codes may apply }\end{array}$ \\
\hline & Scope & $\begin{array}{l}\text { It Identifies if the paper addresses the general SCF } \\
\text { approach or a specific solution }\end{array}$ \\
\hline \multirow[t]{4}{*}{ Themes } & $\begin{array}{l}\text { Definition and } \\
\text { concept }\end{array}$ & $\begin{array}{l}\text { Coded as "Core" if the article provides a definition of } \\
\text { SCF, "Ancillary" if it contributes to conceptually clarify } \\
\text { the concept without formally attempting to define it, } \\
\text { "None" otherwise }\end{array}$ \\
\hline & $\begin{array}{l}\text { Quantitative } \\
\text { benefits }\end{array}$ & $\begin{array}{l}\text { Coded as "Core" if the article presents a quantification } \\
\text { of the benefit of SCF or SCF solutions (through } \\
\text { analytical models, simulation or quantitative-based } \\
\text { analysis of empirical data), "None" otherwise }\end{array}$ \\
\hline & $\begin{array}{l}\text { Qualitative } \\
\text { benefits }\end{array}$ & $\begin{array}{l}\text { Coded as "Core" if the article is focused on the } \\
\text { definition of intangible or qualitatively describe } \\
\text { tangible benefits of SCF or single SCF solutions, } \\
\text { "Ancillary" if the description of the benefits is used to } \\
\text { support the core content of the paper, "None" otherwise }\end{array}$ \\
\hline & SCF projects & $\begin{array}{l}\text { Coded as "Core" if SCF projects are the focus of the } \\
\text { article (e.g. case study), "Ancillary" if they are } \\
\text { presented and comprehensively described, but are not } \\
\text { the core content, "None" if projects are merely } \\
\text { mentioned or are not present }\end{array}$ \\
\hline
\end{tabular}


Table 2. Research method summary

\begin{tabular}{|l|l|}
\hline Methodology & Number \\
\hline Analytical & 57 \\
\hline Conceptual & 30 \\
\hline Survey & 12 \\
\hline Case study & 13 \\
\hline Simulation & 11 \\
\hline Interviews & 0 \\
\hline Others & 9 \\
\hline
\end{tabular}


Table 3. Supply Chain Finance definitions

\begin{tabular}{|c|c|c|c|c|c|c|c|}
\hline$\#$ & Article & Definition & $\begin{array}{l}\text { (a) Role of } \\
\text { Financial } \\
\text { Institution }\end{array}$ & $\begin{array}{c}\text { (b.i) } \\
\text { Scope: } \\
\text { only RF }\end{array}$ & $\begin{array}{c}\text { (b.ii) Scope: inclusive } \\
\text { of inventory } \\
\text { optimization }\end{array}$ & $\begin{array}{c}\text { (b.iii) Scope: } \\
\text { inclusive of fixed } \\
\text { asset financing }\end{array}$ & $\begin{array}{l}\text { Proposed } \\
\text { perspective }\end{array}$ \\
\hline 1 & Hofmann (2005) & $\begin{array}{l}\text { SCF is an approach for two or more organisations in a supply chain, including } \\
\text { external service providers, to jointly create value through means of planning, steering, } \\
\text { and controlling the flow of financial resources on an inter-organisational level }\end{array}$ & & & & Yes & Supply Chain \\
\hline 2 & $\begin{array}{l}\text { Camerinelli } \\
(2009)\end{array}$ & $\begin{array}{l}\text { SCF is the set of products and services that a financial institution offers to facilitate } \\
\text { the management of the physical and information flows of a supply chain }\end{array}$ & Yes & & & & Finance \\
\hline 3 & $\begin{array}{l}\text { Pfohl and Gomm } \\
(2009)\end{array}$ & $\begin{array}{l}\text { SCF is the inter-company optimisation of financing as well as the integration of } \\
\text { financing processes with customers, suppliers, and service providers in order to } \\
\text { increase the value of all participating companies }\end{array}$ & & & Yes & Yes & Supply Chain \\
\hline 4 & Gomm (2010) & $\begin{array}{l}\text { [SCF is the process of] optimising the financial structure and the cash-flow within the } \\
\text { supply chain }\end{array}$ & & & Yes & Yes & Supply Chain \\
\hline 5 & $\begin{array}{l}\text { X. Chen and } \mathrm{Hu} \\
(2011)\end{array}$ & $\begin{array}{l}\text { SCF, as an innovative financial solution, bridges the bank and capital-constrained } \\
\text { firms in the supply chain, reduces the mismatch risk of supply and demand in the } \\
\text { financial flow, and creates value for supply chain with capital constraints }\end{array}$ & Yes & & & & Finance \\
\hline 6 & $\begin{array}{l}\text { Lamoureux and } \\
\text { Evans }(2011)\end{array}$ & $\begin{array}{l}\text { SCF solutions represent a combination of technology solutions and financial services } \\
\text { that closely connect global value chain anchors, suppliers, financial institutions and, } \\
\text { frequently, technology service providers. They are designed to improve the } \\
\text { effectiveness of financial supply chains by preventing detrimental cost shifting and by } \\
\text { improving the visibility, availability, delivery and cost of cash for all global value } \\
\text { chain participants }\end{array}$ & Yes & & & & Finance \\
\hline 7 & $\begin{array}{l}\text { Grosse-Ruyken } \\
\text { et al. }(2011)\end{array}$ & $\begin{array}{l}\text { [SCF] is an integrated approach that provides visibility and control over all cash- } \\
\text { related processes within a supply chain }{ }^{(a)}\end{array}$ & & & Yes & & Supply Chain \\
\hline 8 & $\begin{array}{l}\text { Wuttke } \text { et al. } \\
\text { (2013a) }\end{array}$ & $\begin{array}{l}\text { we define [FSCM] as optimised planning, managing, and controlling of supply chain } \\
\text { cash flows to facilitate efficient supply chain material flows }{ }^{(b)}\end{array}$ & & & Yes & & Supply Chain \\
\hline 9 & $\begin{array}{l}\text { Wuttke et al. } \\
(2013 b)\end{array}$ & $\begin{array}{l}\text { [SCF is] an automated solution that enables buying firms to use Reverse Factoring } \\
\text { with their entire supplier base, often providing flexibility and transparency of the } \\
\text { payment process }\end{array}$ & Yes & Yes & & & Buyer-driven \\
\hline 10 & $\begin{array}{l}\text { More and Basu } \\
(2013)\end{array}$ & $\begin{array}{l}\text { [SCF] can be defined as managing, planning and controlling all the transaction } \\
\text { activities and processes related to the flow of cash among SC [supply chain] } \\
\text { stakeholders in order to improve their working capital }\end{array}$ & Yes & & & & Finance \\
\hline
\end{tabular}

(a): Based on Camerinelli (2009) and Pfohl and Gomm (2009).

(b): Definition of Financial Supply Chain Management

(c): Definition of Supply Chain Finance 
Table 4. The SCF perspectives identified

\begin{tabular}{|l|l|l|l|l|}
\hline Perspective & $\begin{array}{l}\text { (a) Role of financial } \\
\text { Institution }\end{array}$ & $\begin{array}{l}\text { (b.i) Scope: } \\
\text { only RF }\end{array}$ & $\begin{array}{l}\text { (b.ii) Scope: inclusive of } \\
\text { inventory optimization }\end{array}$ & $\begin{array}{l}\text { (b.iii) Scope: inclusive } \\
\text { of fixed asset financing }\end{array}$ \\
\hline Financial oriented & Mandatory & No & No & No \\
\hline buyer-driven & Mandatory & Yes & No & No \\
\hline $\begin{array}{l}\text { Supply Chain } \\
\text { Oriented }\end{array}$ & Non-mandatory & No & Yes & Sometimes \\
\hline
\end{tabular}

